\title{
OIL PRICE ShoCKS AND ECONOMIC ACtivity: The Asymmetric CoIntegration ApProaCh IN SOUTH AFRICA
}

\author{
Ntokozo Nzimande* \\ University of KwaZulu-Natal
}

Received: September 2015

\author{
Simiso Msomi ${ }^{*}$ \\ University of KwaZulu-Natal
}

Accepted: May 2016

\begin{abstract}
This study examines the link between oil prices and economic activity proxied by gross domestic product in the context of South Africa. The study employs the asymmetric approach proposed by Schorderet (2004) and advanced by Lardic and Mignon (2008). Asymmetric cointegration is used because it is believed that increasing and decreasing oil prices do not have similar or equal impacts on economic activity. In this study we document evidence for an asymmetric response of economic activity to oil price shocks. Further, our findings suggest that negative oil price shocks are important relative to positive oil price shocks.
\end{abstract}

Keywords

Oil prices, economic activity, asymmetric, cointegration

*Mr NP Nzimande is a lecturer in the Department of Economics, University of KwaZulu-Natal, Durban, South Africa [nzimanden3@ukzn.ac.za]

\#Mr SS Msomi is a lecturer in the Department of Economics, University of KwaZulu-Natal, Durban, South Africa. 


\section{INTRODUCTION}

Following Hamilton (1983), a number of studies examined the relationship between oil prices and economic activity using different econometric techniques (see Oladosu, 2009; Cunado \& de Gracia, 2005, among others). The remarkable thing is that these studies have reached a consensus that oil prices can have an adverse impact on economic activity. Simply put, rising energy prices tend to negatively impact economic activity, whereas declining oil prices tend to positively impact economic activity. A few studies argued contrary to what appears to be a consensus; for example, Hooker (1996) found no relationship between macroeconomic variables and oil prices. However, in the mid-1980s is was established that the relationship between oil prices and economic activity is not linear but is asymmetric, such that declining oil prices have a less significant positive impact on economic activity, whereas increasing oil prices have a more adversely significant impact on economic activity (see Mork 1989; Mory, 1993; Brown \& Yucel, 2002; Zhang, 2008; Lardic \& Mignon, 2008, among others). This is perhaps why Hooker (1996) concluded that the relationship between economic activity and oil prices no longer exists. Hence this paper in the South African context follows the method employed by Lardic and Magnon (2008) to account for the asymmetric response of economic activity to energy prices, particularly oil prices.

Most of these studies have focused on developed economies (Gisser \& Goodwin, 1986; Lardic \& Mignon, 2008), particularly the United States and G-7 countries, and those that paid attention to emerging economies focused on Asian countries (Cunado \& de Gracia, 2005, among others). Although there are some studies that paid attention to South Africa, they were mainly concerned with the relationship between oil prices and inflation (Ajmi, Gupta, Babalos \& Hefer, 2015; Chisadza, Dlamini, Gupta \& Modise, 2013 among others). Therefore, this study differs from those in the existing literature because the focus is shifted from developed countries to developing countries, particularly African countries and, to be more precise, South Africa, which is a net oil importer and is argued to be energy intensive (Kohler, 2006).

Over the past years oil consumption in South Africa has increased with a steady increase in economic activity. However, South Africa is a small oil-importing country and, therefore, increasing oil prices could have an adverse effect on economic activity. We believe that through proper policy reaction the undesirable impact of changing oil prices can be reduced. However, to design a proper policy response detailed research on the nature of the relationship between oil prices and economic activity is needed in South Africa. Therefore this study addresses two objectives, (1) we assess the nature of the relationship between oil prices and economic activity using asymmetric cointegration to allow for the possibility of asymmetric relationship as has been documented in the literature and (2) we assess the impact of both increasing and decreasing oil prices on economic activity. Further, this study differs from existing African and South African studies in terms of the methodology that is employed, as we employ asymmetric cointegration, and to the best of our knowledge this method has never been used before in this context. The technique we use was initially developed by Balke and Fomby (1997), Enders and Slikos (2001), Schorderet (2004) and Lardic and Mignon (2008), among others.

Previewing our results, we document the absence of a long-run association between economic activity and oil prices when the traditional (linear) cointegration approach is employed. However, when we employ the asymmetric cointegration approach, we document evidence for an asymmetric long-run association between oil prices and economic activity, with strong evidence for negative oil shocks and weak evidence for positive oil shocks. Further, we found negative 
shocks to have a $0.6 \%$ impact on economic activity and positive oil shocks to have a $0.1 \%$ and insignificant impact on economic activity.

The rest of the study is organised as follows: section 2 provides a concise review of the oil price transmission mechanism in economic activity and a brief review of related literature. Section 3 outlines the methodology employed in the study, section 4 provides and interprets the empirical findings of the study, and lastly, section 5 provides the conclusion and policy recommendations.

\section{OIL PRICE-ECONOMIC ACTIVITY NEXUS}

Rising energy prices, particularly oil prices, indicate the increased scarcity of energy input, which is the most essential input into production. Hence, with a given level of both capital and labour there will be less productivity following an increase in oil prices or rather reduced availability of oil as an input, and thus a potential drop in output. Because productivity falls, real wages will also decline and if rising oil prices are expected to be prolonged, some workers may voluntarily withdraw from the labour market and consequently the natural rate of unemployment rises. However, if consumers are expecting the oil price increase to be temporary they may try to maintain their consumption by either saving less (consuming their savings) or borrowing. To encourage savings or match the increased demand for loans the equilibrium real interest rate will rise and hence the demand for real money balances will decline and the rate of inflation rise. Because input prices (costs of production) have increased, firms will transfer the increased cost of production to consumers in terms of higher prices; this is referred to as the second-round effect. Overall, rising oil prices reduce gross domestic product (GDP) growth, and increase real interest rates and inflation. Mork, Olsen and Mysen (1994) and Brown and Yucel (2002) argued that the impact of rising oil prices can be transmitted to economic activity through the real balance effect. Especially in oil-importing countries consumers will need more currency (Rand in the case of South Africa) to purchase a barrel of oil, hence the demand for balances will rise and the failure of monetary authorities to meet the rising demand induces a rise in the interest rate and thus a deterioration in economic growth (Brown \& Yucel, 2002). The interest rate increases signal the increased cost of borrowing and so discourage large investment with an impact on economic growth. Another channel foregrounded in the literature is the terms of trade. Increasing oil prices imply deteriorating terms of trade for oil-importing countries. Hence income is being transferred from importing countries to exporting countries in the form of high oil prices.

When oil prices are increasing it is always expected that economic growth will be retarded and that when oil prices are declining growth will be stimulated; however, this has not been the case with the recent 2014 decline in oil prices. Mork (1989) failed to find a significant relationship between oil prices and economic activity, but when separating oil prices into negative and positive changes, he found a significant relationship between the two variables. The same conclusions were reached by Mory (1993), who found that positive oil prices shocks had a significant impact on the economy and they Granger cause macroeconomic variables, whereas negative oil shocks did not.

Cunado and de Gracia (2003) studied the relationship between oil prices and the macro economy by means of studying the impact of oil price shocks on inflation and economic activity (proxied by the industrial production index). They found that oil prices have a permanent effect on inflation and a transitory asymmetric effect on economic activity. Cunado and de Gracia (2005) examined the relationship between oil price movements and the macro economy by studying the effect of oil price shocks on economic activity and consumer price indexes for the period $1975 \mathrm{Ql}$ - 
200202. They found that oil prices significantly affect both economic activity and price indexes, although the impact is only transitory. Further, they found evidence for asymmetries in the oil economic activity and price indexes relationship for Asian countries. Zhang (2008) surveyed the link between oil shocks and economic growth in Japan using the non-linear approach developed by Hamilton (2003). He found that a nonlinear relationship exists between oil prices and economic growth. Simply put, increasing oil prices retard economic growth more significantly than declining oil prices stimulate growth. Lardic and Mignon $(2006,2008)$ examined the long-run association between oil prices and economic activity, using the asymmetric cointegration technique. They found that orthodox cointegration is rejected but there is evidence for asymmetric cointegration. $\mathrm{He}$, Wang and Lai (2010) examined the relationship between global economic activity proxied by the Killian economic index and oil prices. They found that a long-run association between Killian and real futures prices of crude oil exists. Hamilton (2003) allowed for a nonlinear relationship between oil prices and economic growth. He found that oil price increases are more important than decreasing oil prices.

\section{ASYMMETRIC COINTEGRATION METHODOLOGY AND DATA}

Two or more series moving together in the long run are said to be cointegrated (Granger, 1981). These series are often referred to as the 'drunk and his blind dog'. This is because, although these series may wander apart in the short run, after some time (i.e. in the long run) they will always come back to each other. This has attracted interest in assessing the relationship between two or more series, such as oil prices and economic growth. However, the challenge in these studies is that they assess linear integration between two or more series (Brown \& Yucel, 2002). Following Hooker's assertion that the oil price-economic activity nexus has broken down, interests in assessing the link between oil prices and economic activity using nonlinear techniques were renewed.

Other studies then concluded that the relationship between oil prices and economic growth did not break down as such, but rather the structure of the relationship has changed (Zhang, 2008). For this and other reasons the need for a model that will be able to assess the changing structure of the relationship between two or more series became a necessity. As a result we employ asymmetric cointegration developed by Schorderet (2004) and applied by Lardic and Mignon (2008) to assess the structure of the relationship between oil prices and economic activity in the United States, G7 and Europe.

Following work done by Lardic and Mignon $(2006,2008)$, in this study we test for asymmetric cointegration. From Schorderet (2003) we apply the necessary condition, which is to decompose time series into positive and negative parts. Schorderet (2003) showed that when starting at a given time series $\left\{V_{t}\right\}_{t=0}^{T}$ is decomposable into initial values of the process.

$$
V_{t}=V_{0}+V_{t}^{+}+V_{t}^{-}
$$

where $V_{0}$ denotes the values that occurs in the beginning

$$
V_{t}^{+}=\sum_{i=0}^{t-1} 1\left\{\Delta V_{t-1} \geq 0\right\} \Delta V_{t-1}
$$


and

$$
V_{t}^{-}=\sum_{i=0}^{t-1} 1\left\{\Delta V_{t-1}<0\right\} \Delta V_{t-1}
$$

$\left\{V_{t}^{+}\right\}_{t=1}^{T}$ and $\left\{V_{t}^{-}\right\}_{t=1}^{T}$ represent positive and negative cumulative shocks, respectively, that describe the level of prices at the initial time, denoted by $t$. When the event in the parenthesis occurs it is represented by 1 , which is the indicator function, and 0 otherwise. Then let us consider series $V_{1 t}$ and $V_{2 t}$ and suppose that these series are both not linearly cointegrated but within them there is a linear relationship denoted by $h_{t}$ such that,

$$
h_{t}=\alpha_{0} V_{1 t}^{+}+\alpha_{1} V_{1 t}^{-}+\alpha_{2} V_{2 t}^{+}+\alpha_{3} V_{2 t}^{-}
$$

Equation (4) consists of a stationary distribution because vector $\alpha^{\prime}=\left(\alpha_{0}, \alpha_{1}, \alpha_{2}, \alpha_{3}\right)$ with $\alpha_{0}$ or $\alpha_{1} \neq 0, \alpha_{2}$ or $\alpha_{3} \neq 0, \alpha_{0} \neq \alpha_{1}, \alpha_{2} \neq \alpha_{3}$ - therefore the time series can be asymmetrically cointegrated. The relationship between the two series is not the same when variables are increasing or decreasing (see Granger \& Yoon, 2003, among others).

Schorderet (2003) argued that if only one component in each series in equation (4) has a cointegrating relationship this might be an indication of a cointegrating relationship that functions in one direction:

$$
\begin{array}{lr}
V_{1 t}^{+}=\alpha^{+} V_{2 t}^{+}+h_{1 t} & \text { where } t=1, \ldots, T \\
V_{1 t}^{-}=\alpha^{-} V_{2 t}^{-}+h_{1 t} & \text { where } t=1, \ldots, T
\end{array}
$$

According to West (1988) we know regressors consist of a linear trend in mean, equation (4) is normally distributed asymptotically and can be estimated using ordinary least squares (OLS) and in addition common statistical inferences are valid; this is a fairly general condition application. The OLS auxiliary model is given by

$$
V_{1 t}^{+}+\Delta V_{1 t}^{-}=\alpha^{+} V_{2 t}^{+}+e_{1 t}
$$

or

$$
V_{1 t}^{-}+\Delta V_{1 t}^{+}=\alpha^{-} V_{2 t}^{-}+e_{1 t}
$$

We use the traditional Engle and Granger approach to test for the hypothesis of no cointegration, against the alternative of no symmetric cointegration between oil prices and GDP in South Africa; we run the test in equations (7) and (8).

We use annually produced data covering the period 1980-2014. Economic activity proxied by real GDP data has been collected from the South Africa Reserve Bank (SARB), crude oil prices in United States (US) dollars were collected from the World Economic Outlook (WEO) IMF database. We collected USD/ZAR (US dollar/South African rand) exchange rate data from SARB and used this to convert oil prices into domestic oil prices, and, lastly, we used the South African consumer price index (CPI) to deflate nominal oil prices to real oil prices; data for the CPI was collected from the SARB. 


\section{EMPIRICAL FINDINGS}

Similar to Lardic and Mignon (2008), in order to examine the statistical properties of the series, we employ two distinct unit root tests: Augmented Dickey-Fuller (ADF) and Phillips-Perron (PP). $T A B L E l$ displays ADF unit root test results, both at levels and at first differences, and, similarly, TABLE 2 displays PP unit root test results, both at levels and in first differences.

TABLE 1: ADF Unit root test results

\begin{tabular}{llc}
\hline \multicolumn{2}{c}{ Augmented Dickey-Fuller Unit Root Test } \\
\hline Variable(s) & series at levels & series in first differences \\
$\ln \varepsilon A$ & $-0.571958(1)$ & $-4.859513 \star \star \star(1)$ \\
$\operatorname{In} \varepsilon A$ & $-2.073170(2)$ & $-4.799252 \star \star \star(2)$ \\
$\ln 0 \mathrm{P}$ & $-0.727654(1)$ & $-5.513039 \star \star \star(1)$ \\
$\ln 0 \mathrm{P}$ & $-1.830923(2)$ & $-5.823085 \star \star \star(2)$ \\
\hline
\end{tabular}

Source: Authors' analysis

Notes: In both the augmented Dickey-Fuller and Phillips-Perron unit root tests (1) represents a model with intercept only and (2) represents a model that consists of both trend and intercept. *** indicates the rejection of a null hypothesis at $1 \%$ level of significance.

TABLE 2: PP Unit root test results

\begin{tabular}{lcc}
\hline & \multicolumn{2}{c}{ Phillips-Perron Unit Root Test } \\
\hline Variable(s) & series at levels & series in first differences \\
$\operatorname{In} \varepsilon A$ & $-1.17787(1)$ & $-4.739940 \star \star \star(1)$ \\
$\ln \varepsilon A$ & $-2.301933(2)$ & $-4.691779 \star \star \star(2)$ \\
$\ln 0 P$ & $-0.673586(1)$ & $-5.535110 \star \star \star(1)$ \\
$\operatorname{In} 0 P$ & $-1.646581(2)$ & $-9.587903 \star \star \star(2)$ \\
\hline
\end{tabular}

Source: Authors' analysis

Notes: In both the augmented Dickey-Fuller and Phillips-Perron unit root tests (1) represents a model with intercept only and (2) represents a model that consists of both trend and intercept. *** indicates the rejection of a null hypothesis at $1 \%$ level of significance.

TABLE 1 and TABLE 2 suggest that the null hypothesis of a unit root cannot be rejected at levels for both model 1 , that is, the model with intercept only, and model 2 , which consists of both intercept and trend. However, both ADF in TABLE 1 and PP in TABLE 2 reject the null hypothesis of a unit root at first differences. Hence, we conclude that series are /(1). These findings are similar to those of Cunado and de Gracia (2003) and Cologni and Manera (2009), in the case of European countries and China, respectively. 
TABLE 3: Standard Cointegration (ADF Test on Residuals)

\begin{tabular}{lc}
\hline & Augmented Dickey-Fuller Unit Root Test: Residuals \\
\hline Residuals & $-2.514339(1)$ \\
Residuals & $-2.349129(2)$ \\
& Phillips-Perron Unit Root Test: $R$ Residuals \\
Residuals & $-2.679056(1)$ \\
Residuals & $-2.152811(2)$ \\
\hline
\end{tabular}

Source: Authors' analysis

The stationarity properties of the data were examined and it was established that oil prices and GDP are cointegrated of order one. We examined the orthodox cointegration between oil prices and GDP. Conventional cointegration suggests that there is no long-run association between oil prices and economic activity. Simply put, relying on the ADF and PP unit root tests we failed to reject the null hypothesis of a unit root on the residuals. Put differently, our results suggest that when using the traditional (linear) cointegration technique the relationship between oil prices and economic activity is constrained only to a short run. These results are similar to those found by Lardic and Mignon (2008) and Cunado and de Gracia (2005).

The failure to find a cointegrating relationship between economic activity and oil prices suggests that the impact of oil prices is limited only to the short run and therefore oil price shocks do not affect economic activity in the long run. Lardic and Mignon (2008) argued that the failure to find a long-run relationship between oil prices and economic activity could be because standard cointegration is too restrictive. Hence, we apply asymmetric cointegration to further scrutinise the relationship between oil prices and economic activity.

TABLE 4: Unit Root test on residuals-positive component of oil prices

\begin{tabular}{|c|c|}
\hline \multicolumn{2}{|c|}{ Augmented Dickey-Fuller Unit Root Test: residuals++ } \\
\hline Residuals & $-4.860513 * \star \star(1)$ \\
\hline Residuals & $-4.813008 * \star \star(2)$ \\
\hline \multicolumn{2}{|c|}{ Phillips-Perron Unit Root Test: Residuals++ } \\
\hline Residuals & $-4.737366 * \star \star(1)$ \\
\hline Residuals & $-4.680542 \star \star \star(2)$ \\
\hline
\end{tabular}

Source: Authors' analysis 
TABLE 5: Unit root tests on Residuals-Negative Component of oil prices

\begin{tabular}{lc}
\hline & Augmented Dickey-Fuller Unit Root Test: Residuals-- \\
\hline Residuals & $-5.383302 \star \star \star(1)$ \\
Residuals & $-5.321444 * \star \star(2)$ \\
& Phillips-Perron Unit Root Test: $R$ Residuals-- \\
Residuals & $-5.333776 \star \star \star(1)$ \\
Residuals & $-5.269633 \star \star \star(2)$ \\
\hline
\end{tabular}

Source: Authors' analysis

In contrast to what has been documented in the literature, our findings suggest that, indeed, the association between oil prices is asymmetric.

Although we find evidence for an asymmetric economic activity response, the response contradicts the findings of previous studies (see Mork, 1989; Mork et al., 1994; Cunado \& de Gracia, 2003; Ferderer, 1996, among others).

TABLE 6: Oil Prices and Economic Activity Regression: Decomposed Data

\begin{tabular}{lcc}
\hline Variable & Coefficient & P-value \\
\hline OP1 & $0.060^{\star \star}$ & 0.0158 \\
& $(0.023)$ & \\
OP2 & 0.016 & 0.6215 \\
& $(0.026)$ & \\
\hline
\end{tabular}

Source: Authors' analysis

** represents $5 \%$ level of significance. Standard errors are given in parenthesis

NB: OP1 denotes decreasing oil prices and OP2 increasing oil prices

When we ran regressions for both negative and positive values we found that a $10 \%$ decline in oil prices significantly improves economic activity by $0.6 \%$, whereas an increase in oil prices does not significantly impact on economic activity: the coefficient is $0.1 \%$ for a $10 \%$ increase in oil price. The elasticities have been estimated by decomposing real oil prices into positive and negative components (see Mork, 1989). The possible explanation for the insignificant impact of oil prices on economic activity could be that although South Africa is a net importer of oil, the economy is not oil intensive; rather the economy is largely dependent on abundantly available and cheap coal. In 2004, the South African Department of Energy developed a biofuel strategy to contribute to the production of renewable energy using agriculture and to reduce the dependence on crude oil. Indeed, our findings show that South Africa is not very vulnerable to positive oil shocks. Nkomo (2006) showed that South Africa's oil vulnerability was 0.034 and energy intensity was falling, therefore signalling the declining vulnerability to oil shocks. Mishkin and Shimdit-Hebbel (2007) argued that countries with inflation targeting are less likely to be severely adversely influenced by oil price shocks. Hence this study indeed lends support to this argument. Although our elasticities are different from what other studies have found, they are able to indicate that economic activity is not similar when oil prices increase compared to when they decrease. 
The significant positive impact of declining oil prices on economic growth can possibly be explained by the basic law of demand assertions. For a given level of technology and labour, decreasing oil prices improve productivity and hence economic activity. Put differently, decreasing oil prices reduce the costs of production for oil intensity sectors and hence induce more production and thus employment, therefore increasing economic activity.

\section{SUMMARY AND CONCLUSIONS}

In this paper we examined the long-run relationship between oil prices and economic activity proxied by the GDP for the period of 1966-2014, using South African data. Unit root analysis, both the ADF and PP, suggested that series are not stationary at levels; however, they are stationary at first differences. Using a standard cointegration approach we examined the long-run association between the two variables employed in this study. Contrary to existing studies (Lardic and Mignon, 2008, among others), we found that there is no long-run relationship between oil prices and economic activity. Failure to find a long-run association could be owing to the fact pointed out by Lardic and Mignon $(2006,2008)$ : that standard cointegration is too restrictive, and given that Mork (1989) pointed out that the structure of the relationship between oil prices and economic activity has changed. Simply put, the relationship is no longer linear; however, it is asymmetric. We therefore examined the oil price economic activity nexus using an asymmetric cointegration approach developed by Schorderet (2004). Using an asymmetric cointegration approach, our findings support the existing literature that economic activity responds asymmetrically to oil price shocks, such that an increase in energy prices does not affect economic activity, whereas a decrease in oil prices stimulates economic activity.

Overall, although we find evidence for asymmetric cointegration between economic activity and oil prices, South Africa is not vulnerable to positive oil price shocks. This could be explained by South Africa's reliance on cheap and abundantly available coal. However, Cunado and de Gracia (2003) argued that the choice of modelling oil prices is essential - that is, whether one chooses to use national prices or world prices. Thus, for further studies we suggest that cognisance is taken of national prices and also the importance of structural breaks should be taken into account. It is believed that structural breaks could alter the relationship if not taken into account (Hooker, 1996; Cunado \& de Gracia, 2003). Having established the documented evidence for asymmetric cointegration, the question is how monetary authorities should react to oil price shocks. We suggest that contrary to the conventional belief that positive oil shocks are more important than negative oil shocks, monetary authorities should not worry too much about positive oil shocks, depending on the longevity of the shocks. However, monetary authorities should put more emphasis on declining oil prices, because they could lead to so-called demand-driven inflation. 


\section{Acknowledgement}

The authors would like to acknowledge Dr Harold Ngalawa, Lenhle Dlamini, Nwabisa Ndzama, Adebayor Kutu and Christian Tipoy for their meaningful comments on the first draft. We would also like to thank all participants of the Macroeconomic Working Group (MWG), and, lastly, thanks to all participants at the University of KwaZulu-Natal, College of Law and Management Studies college research day.

\section{LIST OF REFERENCES}

Ajmi, A., Gupta, R., Babalos, V., \& Hefer, R. (2015). Oil price and consumer price nexus in South Africa revisited: A novel asymmetric causality approach. Energy, Exploration \& Exploitation, 33(1), pp. 6374.

Balke, N.S., \& Fomby, T.B. (1997). Threshold Cointegration. International Economic Review, 38(3), pp. $627-45$.

Brown, S.P., \& Yücel, M.K. (2002). Energy prices and aggregate economic activity: an interpretative survey. The Quarterly Review of Economics and Finance, 42(2), pp. 193-208.

Chisadza, C., Dlamini, J., Gupta, R., \& Modise, M.P. (2013). The impact of oil shocks on the South African economy. Department of Economics, University of Pretoria. (Working Paper Series No. 201311).

Cologni, A., \& Manera, M. (2008). Oil prices, inflation and interest rates in a structural cointegrated VAR model for the G-7 countries. Energy Economics, 30(3), pp. 856-888.

Cologni, A., \& Manera, M. (2009). The asymmetric effects of oil shocks on output growth: A MarkovSwitching analysis for the G-7 countries. Economic Modelling, 26(1), pp. 1-29.

Cunado, J., \& de Gracia, F.P. (2003). Do oil price shocks matter? Evidence for some European countries. Energy Economics, 25(2), pp. 137-154.

Cunado, J., \& De Gracia, F.P. (2005). Oil prices, economic activity and inflation: Evidence for some Asian countries. The Quarterly Review of Economics and Finance, 45(1), pp. 65-83.

Enders, W., \& Siklos, P.L. (2001). Cointegration and threshold adjustment. Journal of Business \& Economic Statistics, 19(2), pp. 166-176.

Ferderer, J.P. (1997). Oil price volatility and the macroeconomy. Journal of Macroeconomics, 18(1), pp. 1-26.

Gisser, M., \& Goodwin, T.H. (1986). Crude Oil and the Macroeconomy: Tests of Some Popular Notions: A Note. Journal of Money, Credit and Banking, 18(1), 95-103.

Granger, C.W., \& Yoon, G. (2002). Hidden cointegration. University of California, Economics Working Paper, (Working paper series no. 2002-02).

Hamilton, J. (1983). Oil and the Macroeconomy since World War II. Journal of Political Economy, 91(2), pp. 228-48.

Hamilton, J.D. (2003). What is an oil shock? Journal of Econometrics, 113(2), pp. 363-398.

$\mathrm{He}$, Y., Wang, S., \& Lai, K.K. (2010). Global economic activity and crude oil prices: A cointegration analysis. Energy Economics, 32(4), pp. 868-876. 
Hooker, M.A. (1996). What happened to the oil price-macroeconomy relationship? Journal of monetary Economics, 38(2), pp. 195-213.

Hooker, M.A. (2002). Are oil shocks inflationary? Asymmetric and nonlinear specifications versus changes in regime. Journal of Money, Credit, and Banking, 34(2), pp. 540-561.

Kohler, M. (2006). The Economic Impact of Rising Energy Prices: A Constraint on South Africa's Growth and Poverty Reduction Opportunities. In TIPS/DPRU Forum (pp. 18-20).

Lardic, S., \& Mignon, V. (2006). The impact of oil prices on GDP in European countries: An empirical investigation based on asymmetric cointegration. Energy Policy, 34(18), pp. 3910-3915.

Lardic, S., \& Mignon, V. (2008). Oil prices and economic activity: An asymmetric cointegration approach. Energy Economics, 30(3), pp. 847-855.

Mishkin, F. S., \& Schmidt-Hebbel, K. (2007). Does inflation targeting make a difference? National Bureau of $\varepsilon$ conomic Research. (Working paper series no. w12876).

Mork, K.A. (1989). Oil and Macroeconomy When Prices Go Up and Down: An Extension of Hamilton's Results. Journal of Political Economy, 97 (3), pp. 740-44.

Mork, K.A., Olsen, Ø., \& Mysen, H.T. (1994). Macroeconomic responses to oil price increases and decreases in seven $0 E C D$ countries. The Energy Journal, pp. 19-35.

Mory, J.F. (1993). Oil Prices and Economic Activity: Is the Relationship Symmetric?. The Energy Journal, (4), pp. 151-162.

Nkomo, J.C. (2006). Crude oil price movements and their impact on South Africa. Journal of Energy in Southern Africa, 17(4), pp. 25-32.

Oladosu, G. (2009). Identifying the oil price-macro economy relationship: An empirical mode decomposition analysis of US data. Energy Policy, 37(12), pp. 5417-5426.

Schorderet, y. (2003). Asymmetric cointegration. Department of Econometrics, University of Geneva (Working paper series no. 2003.01)

West, K. D. (1988). Asymptotic Normality, When Regressors Have a Unit Root. Econometrica, 56(6), pp. 1397-1417.

Zhang, D. (2008). Oil shock and economic growth in Japan: A nonlinear approach. Energy Economics, 30(5), pp. 2374-2390. 


\title{
A HIDDEN MARKOV MODEL INFERENCE APPROACH TO TESTING THE RANDOM WALK HYPOTHESIS: EMPIRICAL EVIDENCE FROM THE Nigerian StOCK MARKET
}

\author{
Edesiri Nkemnole* \\ University of Lagos
}

Received: October 2015

Accepted: May 2016

\begin{abstract}
The movement of stock prices, in capital markets across the world, has been found to be both random and non-random. Basically, for a stock price to follow a random walk, its future price changes randomly based on all currently available information in the stock market, its price history inclusive. Some research findings have shown that the existing traditional unit root tests have low statistical power and hence cannot capture gradual changes over successive observations. Consequently, there is a need to revisit the random walk theory in stock prices using other tests. This study employs a Hidden Markov Model (HMM) with time-varying parameters to assess whether the stock price movements of the Nigerian Stock Exchange (NSE) follow a random walk process, or otherwise. Via hidden states, the HMM allows for periods with different volatility levels characterised by the hidden states. By simply accounting for the non-constant variance of the data with a two-state Hidden Markov Model and taking estimation into account via the Sequential Monte Carlo Expectation Maximisation (SMCEM) technique, this study finds no support of randomness. In conclusion, the stock price movements of the NSE do not follow the random walk process.
\end{abstract}

Keywords

Hidden Markov Model, random walk theory, stochastic volatility, stock exchange

*Dr EB Nkemnole is a senior lecturer in the Department of Mathematics, University of Lagos, Nigeria [enkemnole@unilag.edu.ng]. 


\section{INTRODUCTION}

Much effort have been put into developing and testing models of stock price index behaviour via random walk theory in finance, as well as empirical literature (Chung \& Hrazdil, 2010; Bariviera, 2011; Lin et al., 2011). Older studies favoured the random walk hypothesis (RWH) as it concerns empirical evidence (Fama, 1965; Niederhoffer \& Osborne, 1966). In a random walk hypothesis, all information contained in historical prices is rapidly reflected in the current market prices. This effectively impedes the opportunity to identify abnormal returns through a trend trading approach. However, some investment strategies are used to exploit trends in prices. In financial economics, the random walk hypothesis warrants further empirical analysis.

The Nigerian stock market is a regulated one; in other words, stock prices are not determined exclusively by the interactions between the forces of demand and supply. The stock prices are basically controlled by an enforced price band by the NSE, which inhibits prices from moving beyond $5 \%$ above and $5 \%$ below at the commencement of a trading day. Using data from stock markets in China, Korea and Taiwan, Lin et al. (2011) established that stock price limits affect stock price randomness. This finding corroborates the findings of Usman (1998) in Nigeria concerning the existence of price bands which limit the full effect of determinants on stock prices as share prices are barred from going beyond $5 \%$ above or $5 \%$ below the prevailing price on any trading day. The existence of influences in the market (Nwidobie, 2013), insider trading and slow pace of provision of market information to the market (Osaze, 2007), and the reliance of stock price determination and market information on previous periods resulted in the description of the Nigerian capital market as effective in the weak-form efficient, where the historical data and prices of the stocks are reflected in the current prices (Adelegan, 2003).

For Gordon (1959), stock values are determined by dividends paid in the immediate preceding period, the growth rate of the dividend and the equity capitalisation rate. Alteration in any of these variables results in a change in the price of that stock. Successive stock values vary as the values of these determinants vary. Fama (1965) maintained that the future price path of stocks is not determinate, as they move as numbers that are random. This movement, for Fama, is possible as the stocks reflect available information, suggesting that successive price changes are independent. This suggestion by Fama (1965) has been put to test in different capital markets across the world with varying outcomes.

This paper examines whether or not the Nigerian stock market is determined by random behaviour. The Augmented Dickey-Fuller (ADF) test and the Hidden Markov Model (HMM) with time-varying properties inference approach are used to study the random walk processes in stock prices.

\section{RELATED LITERATURE}

A lot of research has been done on the random walk of stock returns. I will look at the most relevant ones, as the scope of this study allows.

Research findings from tests for randomness in share price movement show varied recognised determinants of stock price randomness. One of the earliest works on the random movement of stock prices was by Kendall (1953). This work defines the basis for the random walk availability in the stock market prices, which has been tested and empirically evaluated by many researchers all over the world. However, some of them (e.g. Kapetanios et al., 2003; Hasanov \& Omay, 2007) find that stock prices prove unproductive in following the random walk, while a few of them confirm 
the existence of the random walk and a weak form market efficiency in developed, less developed and emerging stock markets of developed and underdeveloped nations.

Ma and Barnes (2001) used the serial correlation, runs and variance ratio tests to index and individual share data for daily, weekly and monthly frequencies. Their finding is that market indices and daily individual share prices in both the Shanghai and Shenzhen stock market demonstrate correlated return patterns, showing that B-shares' prices are more predictable than those of A-shares.

In their analysis of the random walk hypothesis for weekly stock returns, Lo and Mackinlay (1988) tested the RWH for weekly stock market returns by comparing variance estimators derived from data from 1216 sample observations at different frequencies. Their discoveries unequivocally rejected the random walk model for the sample period (1962 to 1985) and for all sub-periods for a variety of aggregate returns indexes and size-sorted portfolios. Keim and Stambaugh (1986), in a bid to refute the suppositions of the random walk theory, realised statistically important predictions of stock prices using predetermined variables. For Fama and French (1987), there is negative serially correlated relationship for long holding-period returns, their conclusion being that $25 \%-40 \%$ of longer horizon returns seem predictable from past returns. This is not in agreement with the findings of Lo and Mackinlay (1988) on the existence of a significant positive serial correlation for weekly and monthly holding-period returns. Al-Loughani (1995), through his application of different statistical devices on the Kuwait stock market (KSM), concluded that KSM does not follow the random walk, as it demonstrates rigidity in its results. Song and Weigen (1995) used the average returns of 29 stocks listed on the Shanghai Stock Exchange (SSE). This study revealed that the SSE is weak over the period of 1993 to 1994.

Wu (1996) assessed the weak-form proficiency of the Shanghai and Shenzhen stock markets, and did not discover weak form efficiency at the bottom line. Dahel and Laabas (1999) studied the efficiency of Gulf Cooperation Council (GCC) equity markets, using data from 1994 to 1998. Their conclusion is that the stock market of Kuwait follows the weak form of efficiency. Abraham et al. (2002) tested the RWH and market efficiency supposition for Saudi Arabia, Kuwait and Bahrain. The findings indicated that Saudi and Bahraini markets follow the hypothesis of random walk, but the market of Kuwait is inefficient and hence did not follow the RWH.

Malkiel (2003) avers that in the case of wholly efficient markets, the present period is not realised by past information. However, the investors are not permitted by the efficient stock markets to get more average returns without facing more average risks. Narayan and Smith (2004), Zivot and Andrews (1992) and Lumsdaine and Papell's (1997) have investigated the effects of structural breaks on the unit root tests process respectively to analyse the random walk hypothesis for stock prices in South Korea.

The findings of this study report that stock prices in South Korea have unit root, hence are consistent with the RWH. Liu (2010) examines the stock market development and market efficiency in the China Stock Market (CSM). By applying the EGARCH test, the study reveals that the CSM is not weak form efficient and does not follow the RWH. Zaubia and Nahlehb (2010) investigated the financial market efficiency in Middle East and North African countries (MENA). The outcome of this study showed that MENA markets follow the RWH and are efficient weakly.

Andersson (2007) opted to use hedging errors in option prices as a measure of the most suitable stochastic process. Through the use of the unit root test and the GARCH $(1,1)$, this study showed that these markets are not weak form efficient and do not follow the RWH. Ali and Mustafa (2001), employing the use of correlation coefficient of successive returns, averages, logarithms and 
regression analysis on daily price data of listed equities, tested this hypothesis in the Pakistani capital market and discovered that information collectively had an effect on stock prices, both negatively and positively. Lo and Mackinlay (1988) variance tests came up with inadequate inferences about the stock price index following a random walk at a fixed significance level. Though such tests can be applied to sequential time periods, they cannot really capture slow changes in efficiency over continual observations. Consequently, the need to re-examine the random walk theory in stock prices by means of other techniques is appropriate.

Research that has tried using other techniques includes Sharma and Kennedy (1977), Nakamura and Small (2007), Fifielda and Jetty (2008), and Borges (2011). Sharma and Kennedy (1977) used runs test and spectral technique to carry out a comparative study between the Bombay Stock Exchange (BSE) and the NySE; they discovered that monthly returns on the BSE were characterised by random walk. Nakamura and Small (2007) used the small-shuffle surrogate method to ascertain random walk characters in the US and Japanese stock returns. Fifielda and Jetty (2008) used parametric and non-parametric variance ratios on the daily data of 370 shares from 19962005 to examine the Chinese A-shares and B-shares market; their findings indicated that random price movements occur.

Globally, the Hidden Markov Models (HMMs) are the most prevalent methods in the machine learning and statistics for modelling sequences. In a statistics framework, the HMM is a composition of two stochastic processes: a Hidden Markov chain, which accounts for temporal variability, and an observable process, which accounts for spectral variability. The combination contains uncertainty status, just like the stock walk trace. Hence, the HMM and the stock walk trace have the same idea by coincidence.

For more than three decades, the HMM has been applied in signal-processing applications, especially in automatic speech recognition. But currently, this theory and application has been extended to other fields. A good example is Kim et al. (1998) who applied the HMM to examine the effects in economic data.

In this study, we will make new use of the HMM to test whether or not the daily returns of the Nigerian Stock Exchange (NSE) from 2010-2014 follow a random walk process.

\section{METHODS}

In this section the models used to explore the random walk are discussed.

\subsection{The Random Walk Model}

The Random Walk Theory holds that in financial markets, prices advance randomly and are not linked. Consequently, the patterns and trends of price changes in a market cannot be used to forecast the future value of financial instruments. More specifically, market efficiency under the random walk model entails that successive price changes of a stock are independently and identically distributed, so the past movement or trend of a stock price or market cannot be used to predict its future movement.

The random walk model due to Campbell et al. (1997) is defined as

$$
x_{t}=x_{t-1}+\varepsilon_{t}, \cdots \xi_{t} \sim \text { i.i.d. }\left(0, \sigma_{t}^{2}\right)
$$


and the increment is defined as

$$
y_{t}=x_{t}-x_{t-1}
$$

$\left\{x_{t}\right\}$ is the process, $\xi_{t}$ is distributed with mean zero and variance $\sigma_{t}^{2}$ and $\left\{y_{t}\right\}$ is the increment sequence.

\subsection{HMM approach with time varying parameters}

Although originally introduced and studied in 1957 and the early 1970s, the contemporary reputation of statistical methods of the HMM is not in question. An HMM is a bivariate discretetime process $\left\{X_{k}, Y_{k}\right\}_{k \geq 0}$ where $\left\{X_{k}\right\}_{k \geq 0}$ is a homogeneous Markov chain which is not directly observed but can only be observed through $\left\{Y_{k}\right\}_{k \geq 0}$ that produce the sequence of observation.

$\left\{Y_{k}\right\}_{k \geq 0}$ is a sequence of independent random variables such that the conditional distribution of $Y_{k}$ only depends on $X_{k}$. The underlying Markov chain $\left\{X_{k}\right\}_{k \geq 0}$ is called the state.

HMMs are defined through a functional representation known as the state space model. The state space model (Doucet \& Johansen, 2009) of an HMM is represented by the following two equations:

(State equation)

$$
x_{t}=f\left(x_{t-1}\right)+w_{t}
$$

(Observation equation)

$$
y_{t}=g\left(x_{t}\right)+v_{t}
$$

where $f$ and $g$ are either linear or nonlinear functions, while $w_{t}$ and $v_{t}$ are error terms. Models represented by (3) - (4) are referred to as state space models and this comprises a class of HMMs with non-linear Gaussian state-space models, for instance, the stochastic volatility (SV) model.

SV model (see Shephard, 1996, for a review) are a variant of the general state space approach presented here. The model belongs to the class of HMM with a non-linear Gaussian state-space model.

The SV model presented by Taylor $(1982,1986)$ accounts for the time-varying parameters and identifies changes towards/from the random walk. The model due to Taylor (1982) can be expressed as an autoregressive (AR) process:

$$
\begin{aligned}
& x_{t}=\phi x_{t-1}+w_{t} \\
& r_{t}=\beta \exp \left(\frac{x_{t}}{2}\right) v_{t}
\end{aligned}
$$

where $w_{t} \sim N(0, \tau), x_{0} \sim N\left(\mu_{0}, \sigma_{0}^{2}\right), v_{t} \sim N(0,1), x_{0}$ is the initial state variable (volatility) at time zero, $\left\{r_{t}\right\}_{t \geq 0}$ is the log-returns on day $t$, we call $\beta$ the constant scaling factor, so that $\left\{x_{t}\right\}_{t \geq 0}$ represents the log of volatility of the data, $\log \left(\sigma_{0}^{2}\right)$ where $\sigma_{0}^{2}=\operatorname{var}\left(r_{t}\right)$.

In order to ensure the stationarity of $r_{t}$, it is assumed that $|\phi|<1 . \phi$ is the autoregressive coefficient ranging from -1 to $l$ for stationarity. Clearly, $\phi$ when reaches one it becomes a random walk model. 
Taking the logarithm of the squared returns of equation (6) results in a linear equation (7),

$$
y_{t}=\alpha+x_{t}+z_{t}
$$

Equations (5) \& (7) form the version of the SV model, which can be modified in many ways; together they form a linear, non-Gaussian, state-space model for which (7) is the observation equation and (6) is the state equation.

$\{\phi, \tau, \alpha\}$ are parameters needed to model the changing volatility. The model integrates an error process in which the variance changes methodically over time. Hence, the model can detect gradual departures from the random walk through time. The mean of the log return depends on its conditional variance. A Sequential Monte Carlo with Expectation Maximisation (SMCEM) technique based on student-t distribution is used to estimate the model. The SMCEM sequentially updates coefficient estimates and generates the set of the parameters and their standard errors (see Kim \& Stoffer, 2008; Nkemnole \& Abass, 2015).

An extension of the linearised version of the SV model (see equations (5) and (7), wherein it is assumed that the observational noise process, $z_{t}$ is a student- $t$ distribution) is considered. The model, first presented in Shumway and Stoffer (2006), retains the state equation for the volatility as

$$
x_{t}=\phi x_{t-1}+w_{t}
$$

but the proposed student- $t$ distribution with degrees of freedom, $v$, for the observation error term, $z_{t}$, effects a change in the observation equation:

$$
y_{t}=\alpha+x_{t}+z_{t}, \quad z_{t} \sim t_{v}, t=1, \cdots, n
$$

For the parameter estimates of the proposed SV model with student- $t$, the likelihood functions have been maximised by using the Sequential Monte Carlo Expectation Maximisation algorithm (Nkemnole et. al., 2014) in the MATLAB optimisation routines.

\subsubsection{Sequential Monte Carlo Expectation Maximisation (SMCEM) Algorithm Analysis - Estimation procedures}

The entire estimation procedure consists of three main steps: filtering, smoothing, and estimation. With the output of filtering and smoothing step an approximate expected likelihood is calculated. $\{\phi, \tau, \alpha\}$ are estimated to model the changing volatility.

\subsubsection{Filtering Step}

The algorithm for the filtering and smoothing steps shows an extension of Godsill et al. (2004) and Kim and Stoffer (2008). From here $M$ samples from $f\left(x_{t}, \mid Y_{t}\right)$ for each $t$ were obtained.

Generate $f_{0}^{(i)} \sim N\left(\mu_{0}, \sigma_{0}^{2}\right)$ for $t=1, \cdots, n$.

Generate a random number $w_{t}^{(i)} \sim N(0, \tau), \quad j=1, \cdots, M$.

Compute $p_{t}^{(i)}=\phi f_{t-1}^{(i)}+w_{t}^{(j)}$.

a. Compute $w_{t}^{(i)}=p\left(y_{t} \mid p_{t}^{(i)},\right) \propto e^{-\frac{x_{t}}{2}}\left(1+\frac{y_{t}^{2} e^{-x_{t}}}{v-2}\right)^{\frac{v+1}{2}}$ 
b. Generate $f_{t}^{(i)}$ by resampling with weights, $w_{t}^{(j)}$.

\subsubsection{Smoothing step}

In the smoothing step, particle smoothers that are needed to get the expected likelihood in the expectation step of the $\varepsilon M$ algorithm were derived:

Suppose that equally weighted particles $\left\{f_{t}^{(i)}\right\}, i=1, \cdots, M$ from $f\left(x_{t}, \mid Y_{t}\right)$ are available for $t=1, \cdots, n$ from the filtering step.

Choose $\left[s_{n}^{(i)}\right]=\left[f_{n}^{(j)}\right]$ with probability $\frac{1}{M}$.

For $n-1$ to 0

Calculate

$w_{t \mid t+1}^{(i)} \propto f\left(s_{t+1}^{(i)} \mid f_{t}^{(j)}\right) \propto \exp \left(-\frac{\left(s_{t+1}^{(i)}-\phi f_{t}^{(j)}\right)^{2}}{2 \tau}\right) \frac{1}{\sqrt{\pi(v-2)}} \frac{\Gamma\left[\frac{v+1}{2}\right]}{\Gamma \frac{v}{2}} \exp ^{-\frac{\tilde{s}_{t+1}}{2}}\left(1+\frac{y_{t}^{2} e^{-\tilde{s}_{t+1}^{(j)}}}{v-2}\right)^{-\frac{v+1}{2}}$

for each $j$

Choose $\left[s_{t}^{(i)}\right]=\left[f_{t}^{(j)}\right]$ with probability $w_{t \mid t+1}^{j}$.

$\left(s_{0: n}^{(i)}\right)=\left\{\left(s_{0}^{(i)}, \cdots, s_{n}^{(i)}\right)\right\}$ is the random sample from $f\left(x_{0}, \cdots, x_{n} \mid Y_{n}\right)$

Repeat $1-3$, for $i=1, \cdots, M$ and calculate

$$
\begin{aligned}
& \hat{x}_{t}^{n}=\frac{\sum_{i=1}^{M} s_{t}^{(i)}}{M}, \hat{p}_{t}^{n}=\frac{\sum_{i=1}^{M}\left(s_{t}^{(i)}-\hat{x}_{t}^{n}\right)^{2}}{M-1}, \hat{p}_{t, t-1}^{n}=\frac{\sum_{i=1}^{M}\left(s_{t}^{(i)}-\hat{x}_{t}^{n}\right)\left(s_{t-1}^{(i)}-\hat{x}_{t-1}^{n}\right)}{M}, \\
& E\left[1+\frac{y_{t}^{2} e^{x_{t}}}{v-2}\right]^{-\frac{v+1}{2}}=\frac{n(v-2)}{(v+1) \sum_{t=1}^{n} y_{t}^{2} e^{-y_{t}+v_{t}}\left[1+\frac{y_{t}^{2} e^{x_{t}}}{v-2}\right]^{-1}}
\end{aligned}
$$

\subsubsection{Estimation Step}

This step consists of obtaining parameter estimates by setting the derivative of the expected likelihood, of the complete data $\left\{x_{0}, \cdots, x_{n}, y_{1}, \cdots, y_{n}\right\}$ given $\left\{x_{0}, \cdots, x_{n}\right\}$, with respect to each parameter to zero and solving for $\hat{\phi}, \hat{\tau}$, and $\hat{\alpha}$.

The complete likelihood of $\left\{x_{0}, x_{1}, \cdots, x_{n}, y_{1}, \cdots, y_{n}\right\}$ is 


$$
\begin{aligned}
& \log f(X, Y)=\log \frac{1}{\sqrt{2 \pi}} \frac{1}{\sigma_{0}}+\log \exp \left(-\frac{\left(x_{0}-\mu_{0}\right)^{2}}{2 \sigma_{0}^{2}}\right)+\log \prod_{t=1}^{n} \frac{1}{\sqrt{2 \pi \tau}} \exp \left(\frac{-\left(x_{t}-\phi x_{t-1}\right)^{2}}{2 \tau}\right) \\
&+\log \prod_{t=1}^{n} \frac{1}{\sqrt{\pi(v-2)}} \frac{\Gamma\left(\frac{v+1}{2}\right)}{\Gamma\left(\frac{v}{2}\right)} e^{-\frac{\left(y_{t}-\alpha-v_{t}\right)}{2}}\left(1+\frac{y_{t}^{2} e^{-\left(y_{t}-\alpha-v_{t}\right.}}{v-2}\right)^{-\frac{v+1}{2}}
\end{aligned}
$$

By the above method, we got the following estimates

$$
\begin{gathered}
\hat{\phi}=\frac{S_{10}}{S_{00}}, \quad \hat{\tau}=\frac{1}{n}\left[S_{11}-\frac{S_{10}^{2}}{S_{00}}\right] \\
\hat{\alpha}=\log \frac{n(v-2)}{(v+1) \sum_{t=1}^{n} y_{t}^{2} e^{-y_{t}+v_{t}}\left[1+\frac{y_{t}^{2} e^{x_{t}}}{v-2}\right]^{-1}} \\
\hat{\alpha}=\log \frac{n(v-2)}{(v+1) \sum_{t=1}^{n} y_{t}^{2} e^{-y_{t}+v_{t}}\left[1+\frac{y_{t}^{2} e^{x_{t}}}{v-2}\right]^{-1}}
\end{gathered}
$$

where

$$
\begin{aligned}
& S_{00}=\sum_{t=1}^{n}\left(x_{t-1}^{n}\right)^{2}+p_{t-1}^{n}, \\
& S_{11}=\sum_{t=1}^{n}\left(x_{t}^{n}\right)^{2}-p_{t}^{n}, \quad S_{10}=\sum_{t=1}^{n} x_{t}^{n} x_{t-1}^{n}+p_{t, t-1}^{n}
\end{aligned}
$$

\section{EMPIRICAL RESULTS AND DISCUSSION}

This section discusses data collection and analysis. Here, we will also discuss the results of the ADF tests to the random walk process. Lastly, results from the HMM model with time-varying parameters approach are also discussed and compared to the ADF tests.

\subsection{Data employed}

The sample data used for this study is drawn from the daily stock prices of five firms of the NSE, in Banking (GTB), Oil \& Gas (OANDO), Construction (Juius Berger), Health care (Glaxo Smith) and Industrial goods (Chemical \& Applied Product (CAP)) over the period 2 January 2010 to 31 December 2014. 
The data series is transformed into log returns series so that we get stationary series. The transformation is:

$y_{t}=\log \left(\frac{p_{t}}{p_{t-1}}\right)=\log \left(p_{t}\right)-\log \left(p_{t-1}\right)=p_{t}-p_{t-1}$

Where $p_{t}$ is the price of stock at time $t$.

A descriptive statistical summary is obtained to view the data for the daily stock prices and returns of all the indices.

TABLE 1 reports the descriptive statistics for all five selected indices. The positive skewness and kurtosis indicated non-normal series. With reference to Jarque-Bera statistics, the stock index series is non-normal at the confidence interval of $99 \%$, since probability is 0.000000 , which is less than 0.01 .

TABLE 1: Descriptive statistical summary for the daily stock prices

\begin{tabular}{lcccccc}
\hline Index & Mean & Std. Dev. & Skewness & Kurtosiss & Jarque-Bera & Probability \\
\hline GTB & 40.375 & 18.457 & 0.671 & 3.348 & 194.387 & 0.000 \\
OANDO & 70.974 & 47.483 & 1.029 & 4.844 & 202.394 & 0.000 \\
JBERGER & 46.888 & 25.541 & 0.993 & 4.256 & 207.281 & 0.000 \\
GLAXOSMITH & 76.987 & 48.253 & 1.154 & 4.234 & 213.237 & 0.000 \\
CAP & 49.34 & 27.377 & 0.278 & 3.684 & 195.142 & 0.000 \\
\hline
\end{tabular}

Source: Author's analysis

GTB

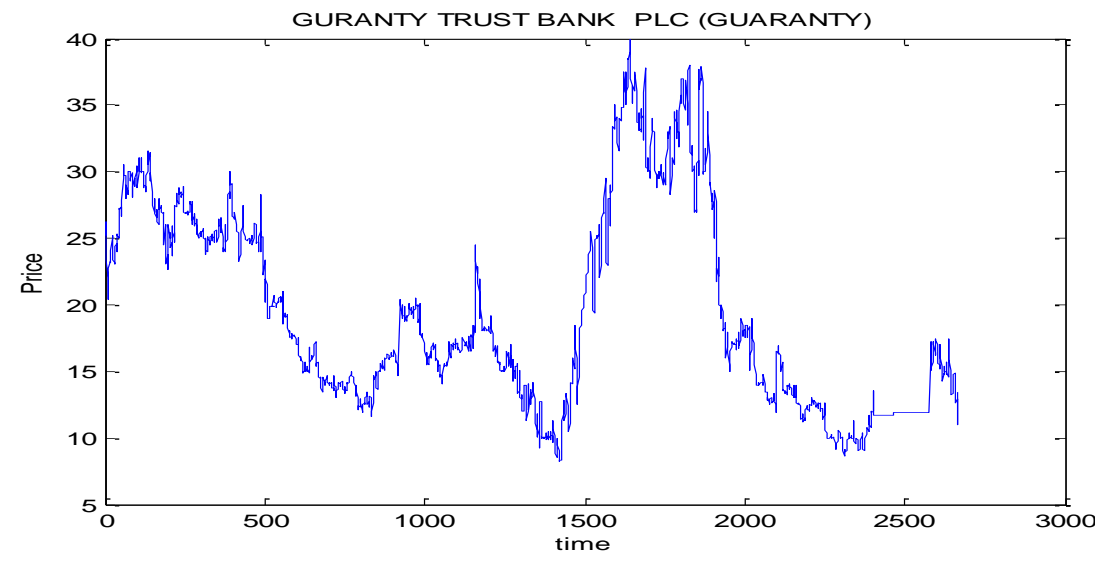


A HIDDEN MARKOV MODEL INFERENCE APPROACH TO TESTING THE RANDOM WALK HYPOTHESIS

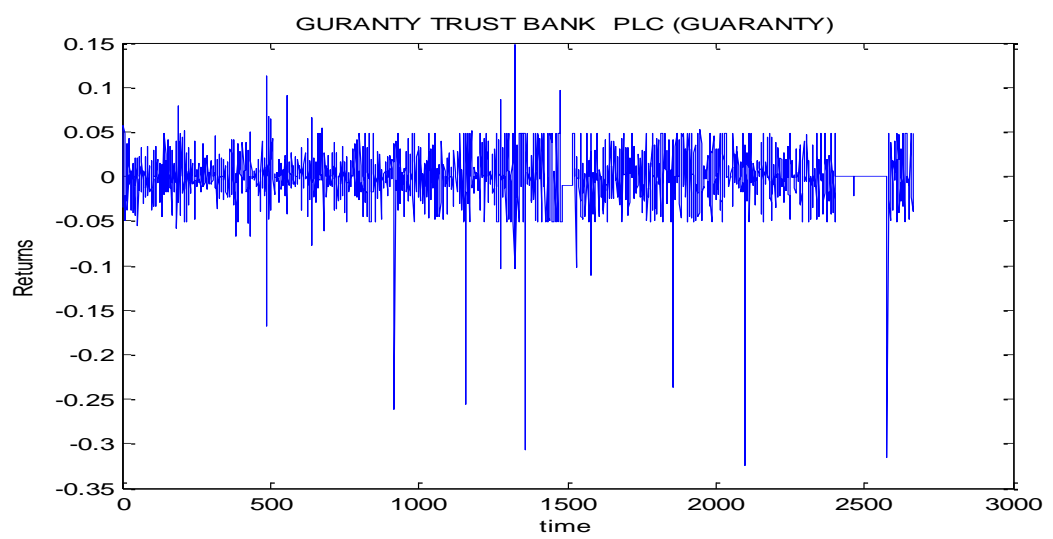

OANDO
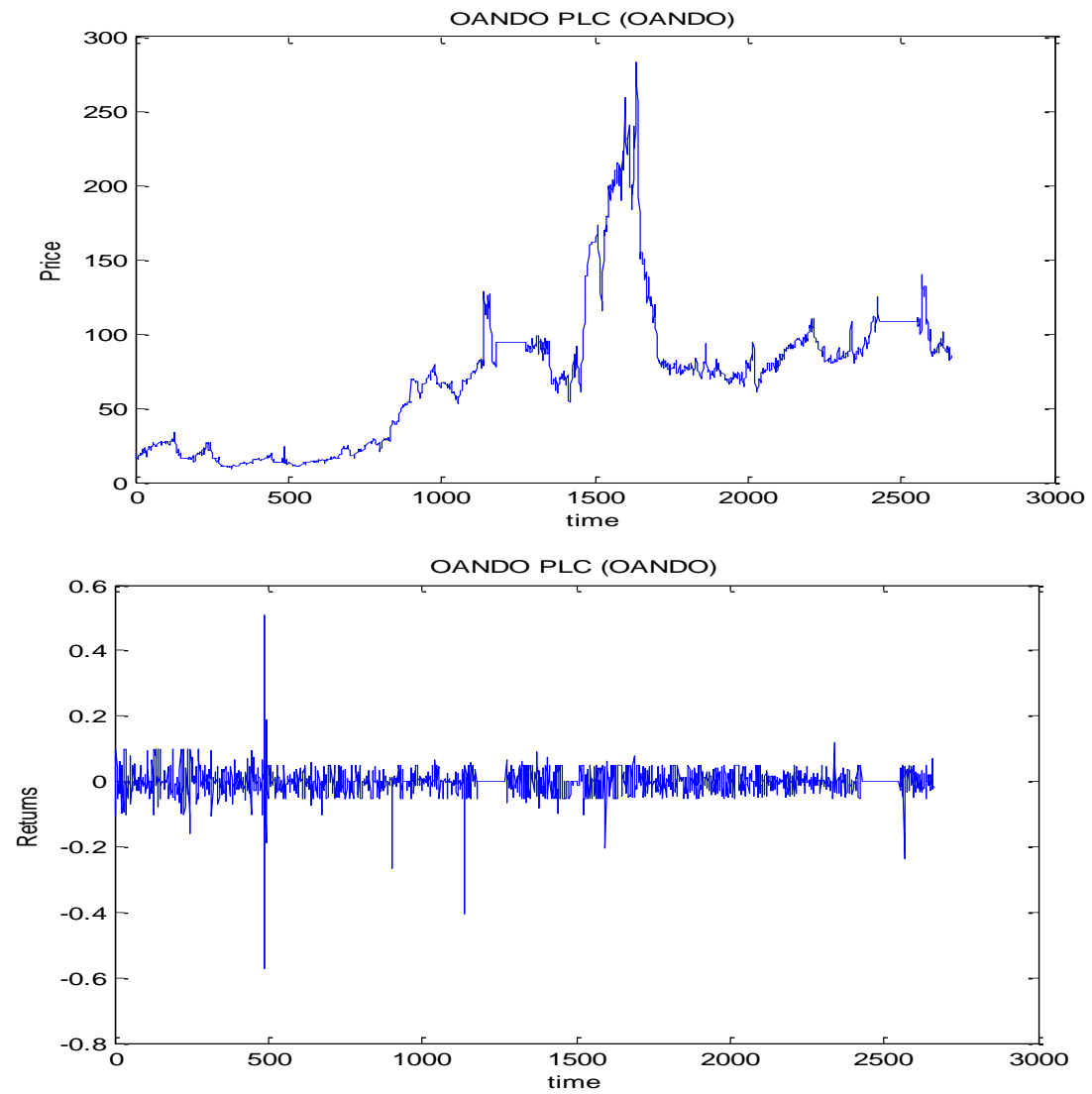
JBERGER
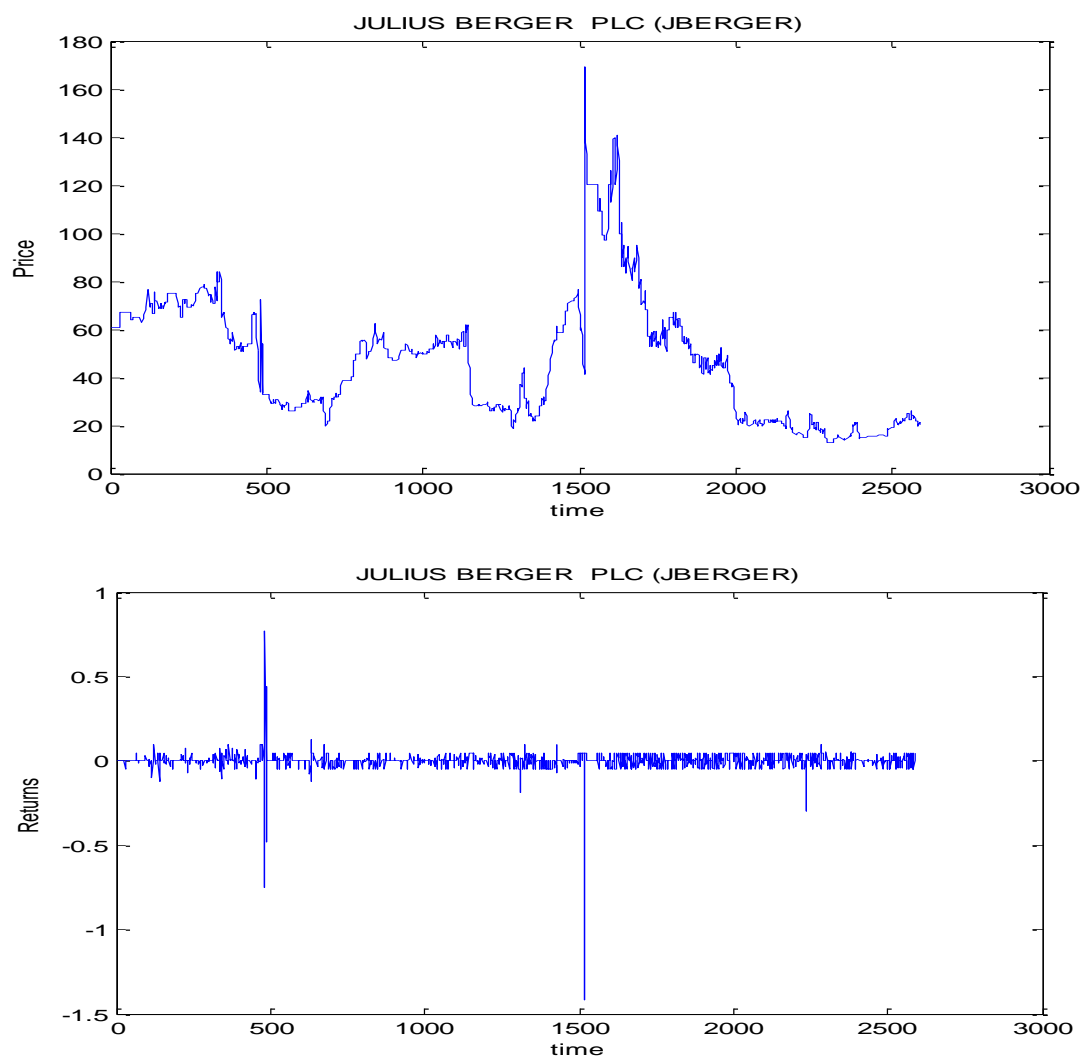

\section{GLAXOSMITH}

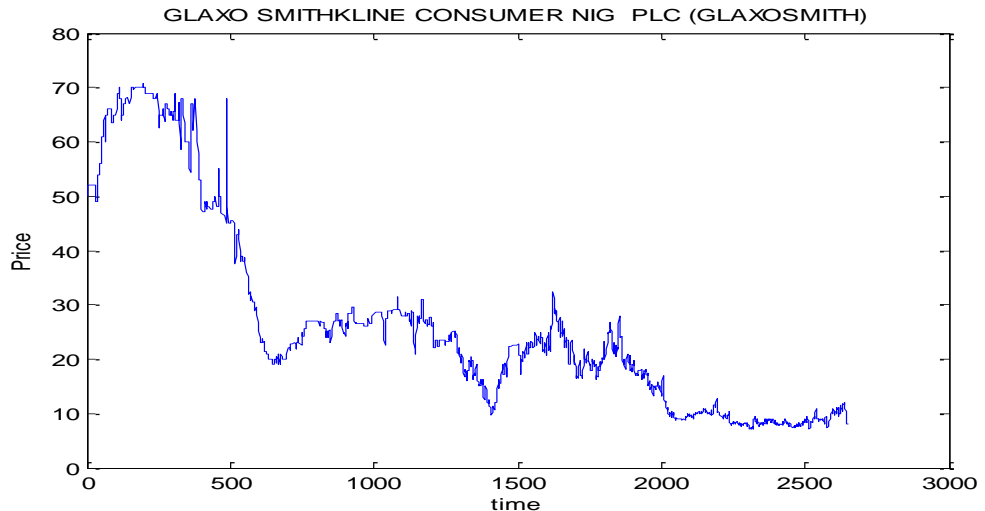




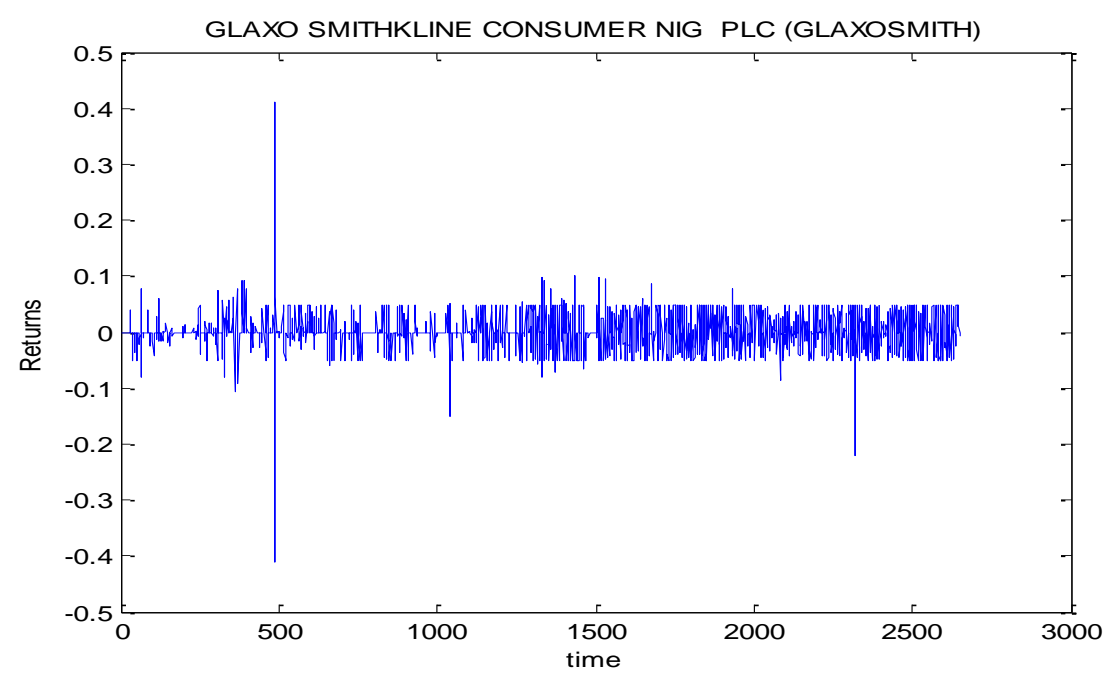

CAP
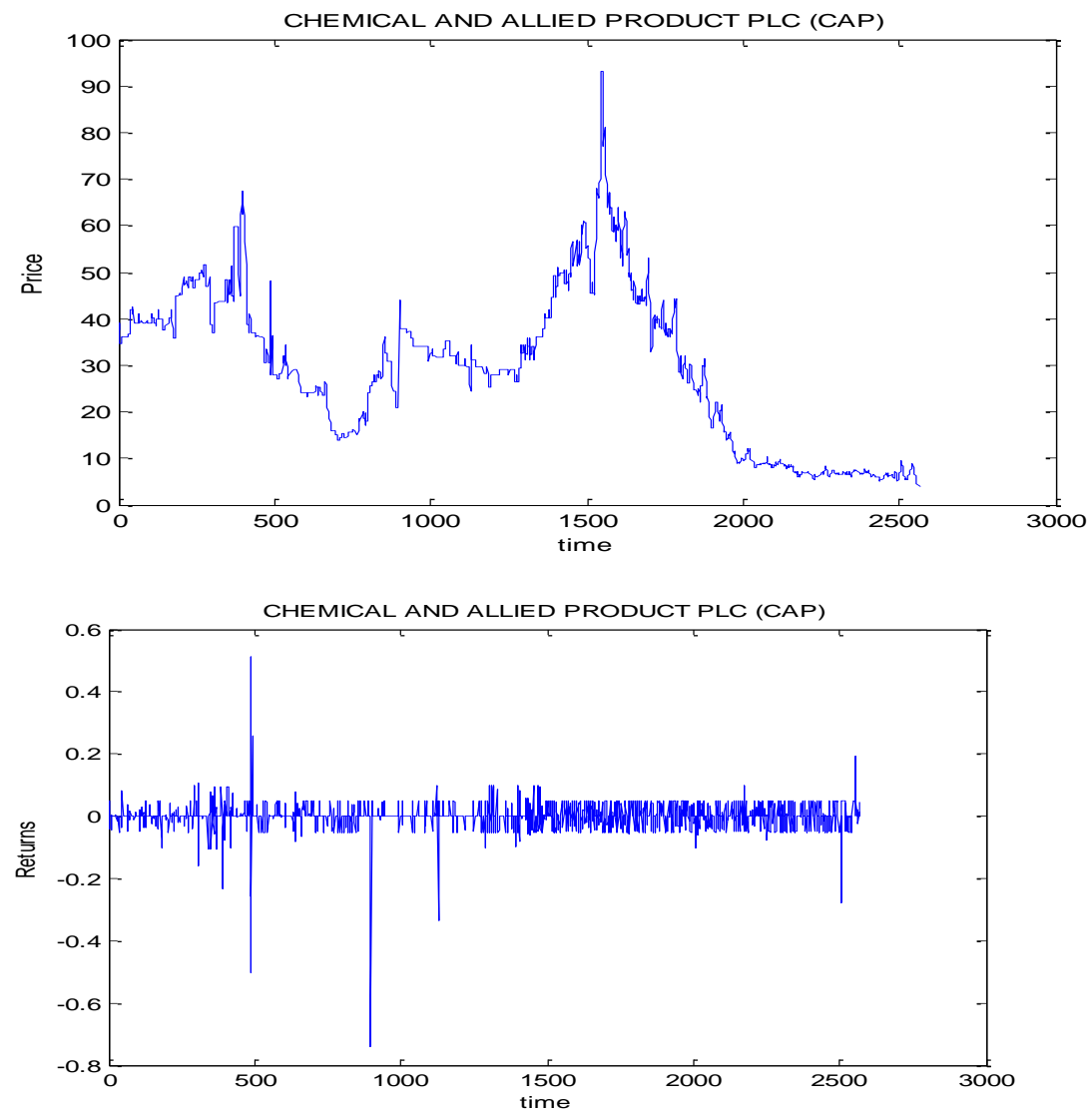

FIGURE 1: Plot for all the five selected stock prices and log returns 


\subsection{Transformation of the stock index series of the NSE}

On the whole, the movements of the stock indices series are non-stationary, and therefore not suitable for the purposes of this study. The stock indices series are transformed into their returns.

\subsubsection{Augmented Dickey-Fuller (ADF) Test}

The ADF test is used to obtain verification regarding whether the NSE return series is stationary or not.

TABLE 2: ADF test for NSE index

\begin{tabular}{|c|c|c|c|c|c|c|}
\hline \multicolumn{7}{|c|}{$\mathrm{t}$-Statistic } \\
\hline & & GTB index & $\begin{array}{l}\text { OANDO } \\
\text { index }\end{array}$ & $\begin{array}{l}\text { JBERGER } \\
\text { index }\end{array}$ & $\begin{array}{l}\text { GLAXOSMITH } \\
\text { index }\end{array}$ & CAP \\
\hline \multirow[t]{3}{*}{$\begin{array}{l}\text { ADF test } \\
\text { statistic }\end{array}$} & & -40.021 & -41.441 & -43.224 & -42.663 & -40.325 \\
\hline & $1 \%$ level & -4.752 & -4.657 & -4.031 & -4.812 & -4.412 \\
\hline & $5 \%$ level & -3.640 & -3.552 & -3.742 & -3.441 & -3.460 \\
\hline $\begin{array}{l}\text { Test } \\
\text { critical } \\
\text { values }\end{array}$ & $10 \%$ level & -3.665 & -3.566 & -3.406 & -3.456 & -3.44 \\
\hline Prob. & & 0.0001 & 0.0001 & 0.0001 & 0.0001 & 0.0001 \\
\hline
\end{tabular}

Source: Author's analysis

TABLE 2 shows that the values of the ADF test statistic of all the NSE index series $(-40.021,-41.441$, $-43.224,-42.663$, and -40.325$)$ are less than the test critical values $(-3.640,-3.552,-3.742,-$ 3.441 , and -3.460 respectively at the $5 \%$ level of significance), which implies that the NSE index series are stationary. Non-stationarity implies the random walk German (2007).

TABLE 3: Summary Statistics of the index returns series

\begin{tabular}{lcccccc}
\hline \multicolumn{1}{c}{ Index } & Mean & Std. Dev. & Skewness & Kurtosis & $\begin{array}{c}\text { Jarque- } \\
\text { Bera }\end{array}$ & Probability \\
\hline GTB & 0.003 & 0.027 & -2.473 & 29.468 & 684.195 & 0.000 \\
OAND0 & -0.001 & 0.035 & -1.303 & 54.496 & 312.573 & 0.000 \\
JBERGER & 0.004 & 0.045 & -1.554 & 42.651 & 497.263 & 0.000 \\
GLAXOSMITH & 0.007 & 0.030 & -0.191 & 30.232 & 513.240 & 0.000 \\
CAP & 0.001 & 0.037 & -3.678 & 20.794 & 795.142 & 0.000 \\
\hline
\end{tabular}

Source: Author's analysis

TABLE 3 reveals a negative skewness, and significant excess kurtosis for all the indices. With reference to the Jarque-Bera statistics, the stock index series is non-normal at the confidence interval of $99 \%$. 
As the actual volatility at time $t$ is not observable, there is need for some measures of volatility to assess the forecasting performance. In this paper we apply the standard approach suggested by Pagan and Schwert (1990). A proxy for the actual volatility $\hat{\sigma}_{t}^{2}$ is given by

$$
\hat{\sigma}_{t}^{2}=\left(r_{t}-\bar{r}\right)^{2}
$$

where $\bar{r}$ is the mean of the time series over the sample period. The statistical performance measures Mean Absolute Percentage Error (MAPE) are applied to see the predictive exactness.

$$
\text { MAPE }=\frac{\sum_{t=1}^{n}\left|\hat{\sigma}_{t}^{2}-\sigma_{t}^{2}\right| \div \sigma_{t}^{2}}{n}
$$

where $\hat{\sigma}^{2}$ is the forecasted variance and $\sigma^{2}$ the actual variance time period $t$ and $n$ is the number of forecasts.

\subsubsection{Statistical performance}

The evaluation results are shown in TABLES 4 and 5. A two-state HMM model was used in our experiments. In the table, $\mathrm{t}-\mathrm{v}$ represents true value, while $s_{1}$ and $S_{2}$ designate the two states with low and high volatility levels, respectively.

TABLE 4: Statistical performance results for the simulated data set and the true parameter sets compared with those obtained from HMM-SV

\begin{tabular}{ccccccc}
\hline \multicolumn{2}{r}{ Models } & $\boldsymbol{\phi}$ & $\boldsymbol{\tau}$ & $\boldsymbol{\alpha}$ & MAPE & p-values \\
\hline \multirow{2}{*}{$\mathrm{t}-\mathrm{v}$} & S1 & 0.63 & 0.850 & 2.166 & & \\
& S2 & 0.70 & 1.254 & 2.094 & & \\
\multirow{2}{*}{ HMMSV } & S1 & 0.64 & 1.365 & 2.146 & & \\
& S2 & 0.78 & 1.353 & 2.113 & 0.111 & 0.075 \\
\hline
\end{tabular}

Source: Author's analysis

TABLE 5: Statistical performance results from HMM-SV model

\begin{tabular}{lrrrrrr}
\hline Index & Model & $\boldsymbol{\phi}$ & $\boldsymbol{\tau}$ & $\boldsymbol{\alpha}$ & MAPE & $p$-values \\
\hline GTB & HMMSV S1 & 0.787 & 3.477 & 6.998 & & \\
& S2 & 0.068 & 1.234 & 3.874 & 0.067 & 0.041 \\
\hline \multirow{2}{*}{ OAND0 } & HMMSV S1 & 0.812 & 4.236 & 4.714 & & \\
& S2 & 0.071 & 3.113 & 2.134 & 0.071 & 0.038 \\
& & & & & & \\
\hline JBERGER & HMMSV S1 & 0.905 & 1.313 & 0.988 & & \\
\hline
\end{tabular}




\begin{tabular}{lrrrrrl}
\hline \multicolumn{1}{c}{ Index } & Model & $\boldsymbol{\phi}$ & $\boldsymbol{\tau}$ & $\boldsymbol{\alpha}$ & MAPE & p-values \\
\hline GLAXOSMITH & HMMSV S1 & 0.887 & 1.460 & 1.259 & & \\
\multirow{2}{*}{ CAP } & S2 & 0.076 & 1.360 & 1.159 & 0.095 & 0.023 \\
& HMMSV S1 & 0.869 & 2.151 & 0.765 & & \\
\hline & S2 & 0.065 & 1.353 & 1.159 & 0.096 & 0.010 \\
\hline
\end{tabular}

Source: Author's analysis

The above results show that that HMM model captures the volatility structure changes processes between two different volatility regimes with different volatility persistence $\boldsymbol{\phi}$ with $p$-values of $.041, .038, .031, .023$, and .010 for each of the stocks respectively. The parameter estimates are statistically significant at the $5 \%$ significance level. From the research results, we conclude that Nigerian stock prices do not follow the random walk pattern described by Fama (1965). Basically, the HMM-SV model offers better volatility forecasts, as the MAPE are 0.067, 0.071, 0.061, 0.0956 and 0.096 . Hence, the predictive exactness is high.

\subsection{Discussion}

In this paper, a HMM is introduced to test whether or not the daily returns of the Nigerian Stock Exchange (NSE) follow a random walk process.

The descriptive statistics for the five indices of the NSE are given in TABLE 3. The highest average returns are obtained in GLAXOSMITH. The JBERGER and GTB are the other indices, which show higher mean returns. This reflects the performance of these indices. Further, the JBERGER has the highest standard deviation (0.045), which represents higher volatility, while the lowest is of GTB (0.027). The returns of the five selected indices are negatively skewed, indicating that the returns are flatter to the left compared to the normal distribution. The significant kurtosis indicates that return distribution has sharp peaks compared to a normal distribution. The Jarque-Bera (1980) statistic confirmed that index returns are non-normally distributed.

The ADF test given in TABLE 2 for all the NSE index series indicates that the NSE index series are stationary. The ADF test statistic is less than its test critical value respectively at the $5 \%$ level of significance. Non-stationarity implies a random walk pattern (German, 2007).

This study demonstrates that the HMM model forecasts very well in the stock recognition domain. The model captures the volatility structure changes processes between two different volatility regimes with different volatility persistence $\phi$ with $p$-values of $.041, .0385, .0313, .0234$ and .0106 for each of the stock respectively (see TABLES 4 and 5). The parameter estimates are statistically significant at the $5 \%$ significance level. The HMM is highly accurate and the predictive exactness is high, as proved by the MAPE value, which is lower than $10 \%$.

Thus, the statistical performance results from the HMM reveal that the daily returns of the NSE do not follow the random walk pattern. This result corroborates the findings of Nwidobie (2014). The research findings also show that price of equities on the Nigerian Stock Exchange seem to follow a definite path determined by information about the stock and the issuing firms.

Based on the above outcome, it is pertinent that the regulatory authority and policy-making body ensure proper dissemination of information so that price can reflect the information promptly. 


\section{CONCLUSION}

Although we have a considerable amount of literature on random walk and market efficiency, there is no agreement among the scholars concerning random walk and efficiency of the market. Andersson (2007) is of the view that the traditional unit root tests have a low statistical power and that they cannot readily capture gradual changes over successive observations. In this research, a Hidden Markov Model (HMM) with time-varying properties is applied to test whether or not the stock price movements of the NSE follow a random walk process. The Augmented DickeyFuller (ADF) is employed to test for stationarity in the data set from 2 January 2010 to 31 December 2014. The HMM-SV model developed allows for periods with different volatility states in the time series and state-specific SV model within each state. By simply accounting for the non-constant variance of the data with a two-state HMM of student's distribution and taking estimation into account via the SMCEM technique, the empirical results confirm that the stock price movements on the NSE do not follow the random walk pattern described by Fama (1965) i.e. are not random. This result corroborates the findings of Nwidobie (2014), Kapetanios et al. (2003) and Lo and Mackinlay (1988; 1987).

\section{LIST OF REFERENCES}

Abraham, A., Fazal, J. \& Sulaiman, A. (2002). Testing the random walk behavior and efficiency of the gulf stock markets. The Financial Review, 37, pp. 469-480.

Adelegan, 0.J. (2003). Capital market efficiency and the effects of dividend announcements on share prices in Nigeria. African Development Review, 15(3), pp. 218-236.

Ali, S.S. \& Mustafa, K. (2001). Testing semi-strong form efficiency of stock market. The Pakistan Development Review, 40(4), pp. 651-674.

Al-Loughani, N.E. (1995). Random walk in thinly traded stock markets: The case of Kuwait. Arab Journal of Administration Science, 3, pp. 189-209.

Andersson, H.(2007). Are commodity prices mean reverting? Applied Financial Economics, 17, pp. 769783.

Bariviera, A.F. (2011). The influence of liquidity on informational efficiency. The case of the Thai stock market. Physica A, 390, pp. 4426-4432.

Borges, M.R. (2011). Efficient market hypothesis in European stock markets. The European Journal of Finance, 16(7), pp. 711-726.

Campbell, J.Y., Lo, A.W. \& Mackinlay, A.C. (1997). The Econometrics of Financial Markets. Princeton: Princeton University Press.

Chung, D. \& Hrazdil, K. (2010). Liquidity and market efficiency: A large sample study. Journa/ of Banking \& Finance, 34, pp. 2346-2357.

Dahel, R. \& Laabas, B. (1999). The behavior of stock prices in the GCC Markets. Journal of Development and Economic Policies, 1, pp. 89-105.

Doucet, A. \& Johansen, A.M. (2009). A Tutorial on Particle Filtering and Smoothing: Fifteen years later. In Crisan, D. \& Rozovsky, B. (eds.) Oxford Handbook of Nonlinear Filtering. Oxford University Press. (pp. 656-704). 
Fama, દ. (1965). The behavior of stock market prices. Journal of Business, 38, pp. 34-105.

Fama, દ. (1970). Efficient capital markets: A review of theory and empirical work. Journal of Finance, 25(2), pp. 383-417.

Fama, દ. \& French, K. (1987). Permanent and temporary components of stock prices. Working Paper No. 178. Centre for Research on Security Prices, University of Chicago.

Fifielda, S.G.M. \& Jetty, J. (2008). Further evidence on the efficiency of the Chinese stock markets: A note. Journal of Research in International Business and Finance, 22, pp. 351-361.

Godsill, S., Doucet, A. \& West, M. (2004). Monte Carlo Smoothing For Non-Linear Time Series. Journal of the American Statistical Association, 199, pp. 156-168.

Gordon, M.J. (1959). Dividends, earnings and stock prices. Review of Economics and Statistics, 41, pp. 99-105.

Hasanov, M. \& Omay, T. (2007). Are the transition stock market efficient? Evidence from non-linear unit root tests. Central Bank Review, 2, pp. 1-12.

Kapetanios, G., Shin, Y. \& Snell, A. (2003). A testing for a unit root in the non-linear star framework. Journal of Econometrics, 112, pp. 359-379.

Keim, D. \& Stambaugh, R. (1986). Predicting returns in stock and bond markets. Journal of Financial Economics, 17, pp. 357-390.

Kendall, M.G. (1953). The analysis of economic time series, Part 1: Prices. Journal of the Royal Statistical Society, 116, pp. 11-25.

Kim, C.J., Nelson, C.R. \& Startz, R. (1998). Testing for mean reversion in heteroscedastic data based on Gibbs sampling augmented randomisation. Journal of Empirical Finance, 5, pp. 131-157.

Kim, J. \& Stoffer, D.S. (2008). Fitting stochastic volatility models in the presence of irregular sampling via particle methods and the EM algorithm, Journal of Time Series Analysis, 29(5), pp. 811-833.

Lin, X., Fei, F. \& Wang, Y. (2011). Analysis of the efficiency of the Shanghai stock market: A volatility perspective. Physica A, 390, pp. 3486-3495.

Liu, T. (2010). Stock market development and market efficiency on China stock market. Journal of Chinese Economics and Finance, 3, pp. 5-14.

Lo, A.W. \& Mackinlay, A.C. (1988). Stock market prices do not follow random walks: Evidence from a simple specification test. The Review of Financial Studies, 1(1), pp. 41-66.

Lumsdaine, R.L. \& Papell, D.H. (1997). Multiple trend breaks and the unit root hypothesis. The Review of Economics and Statistics, 79, pp. 212-218.

Ma, S. \& Barnes, M.L. (2001), Are China's stock market really weak-form efficient. Discussion Paper No. 0119. Available: www.adelaide.edu.au.

Malkiel, B.G. (2003). The Efficient Market Hypothesis and its critics. Journal of Economic Perspective, 17, pp. 59-82.

Nakamura, T. \& Small, M. (2006). Tests of the random walk hypothesis for financial data. Physica A, 377, pp. 599-615.

Naryan, P. \& Smith, R. (2004). Is South Korea's stock market efficient? Applied Economic Letters, 11, pp. $707-710$. 
Nkemnole, દ.B. Abass, 0, \& Kasumu, R.K (2013). Parameter estimation of a class of Hidden Markov Model with diagnostics. Journal of Modern Applied Statistical Methods, 12(1), pp. 181-197.

Nkemnole, E.B. \& Abass, 0. (2015), A t-distribution based particle filter for univariate and multivariate stochastic volatility models. Nigerian Mathematical Society, 34(2), pp. 227-242.

Niederhoffer, V. \& Osborne, M.F.M. (1966). Market making and reversal on the stock exchange. Journal of American Statistical Association, 61(316), pp. 897-916.

Nwidobie, B.M. (2014). The random walk theory: An empirical test in the Nigerian Capital Market. Asian Economic and Financial Review, 4(12), pp. 1840-1848.

Osaze, B.E. (2007). Capital markets: African and Global. Lagos: Book House.

Pagan, A.R. \& Schwert, G.W. (1990). Alternative models for conditional stock volatility. Journal of Econometrics, 45, pp. 267-290.

Sharma J.L. \& Kennedy, R.E. (1977). A comparative analysis of stock price behavior on the Bombay, London, and New York stock exchanges. Journal of Financial and Quantitative Analysis, 12 (3), pp. 391413.

Shephard, N. (1996). Statistical aspects of ARCH and stochastic volatility. In D.R. Cox, D.V. Hinkley \& $0 . \varepsilon$. Barndorff- Nielsen (eds.). Time Series Models: London: Chapman and Hall (pp. 1-67).

Shumway, R.H. \& Stoffer, D.S. (2006). Time Series Analysis and its Applications: Springer, New York.

Song, S. \& Jin, W. (1995). Empirical research on efficiency of Shanghai stock market. Economist, 4, pp. 107-113.

Taylor, S.J. (1986). Modeling Financial Time Series. Chichester: Wiley.

Taylor, S.J. (1982). Financial returns modelled by the product of two stochastic Processes - a study of daily sugar prices, 1961-1979. In 0.D. Anderson (ed.) Time Series Analysis: Theory and Practice, 1. New York: Elsevier Science Publishing (pp. 203-226)

Usman, S. (1998). Comparison of the Nigerian capital market with foreign capital markets and lessons therefrom as we approach 2010. Nigeria Financial Review, 7(1), pp. 70-79.

Wu, S. (1996). Efficiency analysis of China stock market. Economic Research, 4, pp. 13-19.

Zaubia, K.A. \& Nahlehb, M.A. (2010). Financial market efficiency: Empirical evidence from some Middle East and North Africa Countries (MENA). International Research Journal of Finance and Economics, 49, pp. 173-184.

Zivot, E. \& Andrews, D.W.K. (1992).Further evidence on the great crash, the oil-price shock, and the unit-root hypothesis. Journal of Business and Economic Statistics, 10, pp. 251-270. 